\title{
URBAN TERRAIN CLIMATOLOGY AND REMOTE SENSING*
}

\section{ROBERT W. PEASE, JOHN E. LEWIS, AND SAMUEL I. OUTCALT}

\begin{abstract}
Urban areas have been conceived of as monolithic heat islands because traditional ground observation techniques do not lend themselves to more specific analyses. Observations of urban energy-exchange obtained from calibrated electro-optical scanners combined with energy budget simulation techniques provide tools to relate the urban land use mosaic to the heat island phenomenon. Maps of surface energy-related phenomena were made from airborne scanner outputs for selected flightpaths across the city of Baltimore, Maryland. Conditions for the flight time were simulated according to the various types of land use using an energy budget simulation model which lends itself to extrapolation of simulated grid-point conditions into a map form. Maps made by simulation compare sufficiently well with those made by aerial observation to encourage further refinement of the simulation approach.
\end{abstract}

A key environmental challenge that faces man is the production of a more hospitable climate in urban areas while minimizing manmade energy inputs. This paper uses surrogate methods to develop some fundamental relationships between surface properties and urban microclimates in order to provide environmental information for national land use planning. Energy relationships of various urban land uses are investigated using measurements

Dr. Pease is Associate Professor in the Department of Earth Sciences at the University of California in Riverside, CA 92502. Dr. Lewis is Assistant Professor of Geography at McGill University in Montreal H3C 3G1, Quebec, Canada. Dr. Outcalt is Associate Professor of Geography at the University of Michigan in Ann Arbor, MI 48104.

* This study is part of an effort by the Geography Program, U. S. Geological Survey, to investigate environmental consequences of land use patterns and changes. See R. H. Alexander, "CARETS-An Experimental Regional Information System Using ERTS Data," Third Earth Resources Technology Satellite1 Symposium (NASA SP-351), Vol. I, Sect. A (National Aeronautics and Space Administration, Goddard Space Flight Center, Washington, D. C., 1974), pp. 505-22. The imaging aircraft for the project reported in this paper was flown by the Environmental Research Institute of Michigan under contract to NASA and in support of U. S. G. S. Contract 14-08-0001-11914 with the University of California, Riverside. This project was funded preliminary to an investigation of the Washington-Baltimore heat island as part of NASA/ Skylab Investigation No. 469. of surface thermal characteristics from remote sensors and by using energy budget simulation models. The modeling techniques expand point or site simulation to a grid from which map distributions can be made. These maps are compared with maps made by aerial observation.

The nature of the urban surface controls the magnitude and partitioning of energy at the earth's surface-to-atmosphere interface. The site properties which affect the local climate are: 1) the thermal properties of the substrates of the many discrete urban surfaces (diffusivity and conductivity), 2) surface aerodynamic roughness, 3 ) surface reflectivity (albedo), and 4) the distribution of surface moisture susceptible to evaporation or transpiration. The combination of properties of the discrete surface elements establishes a mosaic of microclimates within a city; each element has its own particular radiation-energy budget. When surface properties are changed, the phase and amplitude relationships between the components of the partitioned surface energy are perturbed.

To assess these energy-related changes more rapidly and comprehensively, information from multispectral electro-optical scanners operating in an aircraft platform were used to construct radiation maps for the Baltimore, Maryland urban area. This observed information was coupled with the output of a numerical simulation model which develops temperature and energy-related data for the same place and time.

ANNALS OF THE ASSOCIATION OF AMERICAN GEOGRAPHERS Vol. 66, No. 4, December 1976

(1) 1976 by the Association of American Geographers. Printed in U.S.A. 


\section{MAPPING URBAN CLIMATES FROM REMOTELY-SENSED DATA}

The use of airborne platforms for observing urban radiation phenomena is comparable, except in scale, to the micrometeorological investigation of a bare soil surface where local relief elements such as clods and pebbles are commonly less than two centimeters high. The ratio between the heights of these relief elements and the height of a human observer $(1.8 \mathrm{~m})$ is in the range of $1: 100$. If we retain the same ratio for the analysis of urban terrain, where the roughness elements are 30-100 meters high, the eye-height of the observer would be in the realm of 3-10 kilometers. Thus, an airplane passenger at these altitudes views a city with the same relative perspective as the micrometeorologist does his bare soil, the only difference being that of absolute scale. An urban climatologist, using traditional ground observation techniques, in some ways can be compared to an organism 0.05 millimeter tall attempting to gain an understanding of the spatial distribution of energy relationships of a square meter of bare soil by making observations from within it.

This comparison suggests that an instrument on an aircraft platform views urban terrain with a perspective which circumvents an extremely difficult problem faced by ground observers, that of representative site selection. What are the representative points of a heterogeneous urban terrain? The question contains mutually exclusive elements that suggest the answer is, "There are none." A more viable approach is the use of averages taken over different sectors of the urban surface. By so doing, information collected by remote sensing techniques can be a direct input to automated spatial averaging and filtering operations.

\section{The Baltimore Experiment}

To test the feasibility of this concept as well as that of the coupled experiment, a series of imaging flights was made over Baltimore on May 11, 1972 using the M-7 multispectral scanner of the Environmental Research Institute of Michigan (ERIM). The imaging aircraft flew at 1,524 meters $(5,000$ feet) above the surface for three separate thirty-minute periods beginning at 0515,1015 , and 1345 hours EDT respectively (ERIM designations for takeoff times). Flight sequences included a westeast calibration across the northern suburbs of

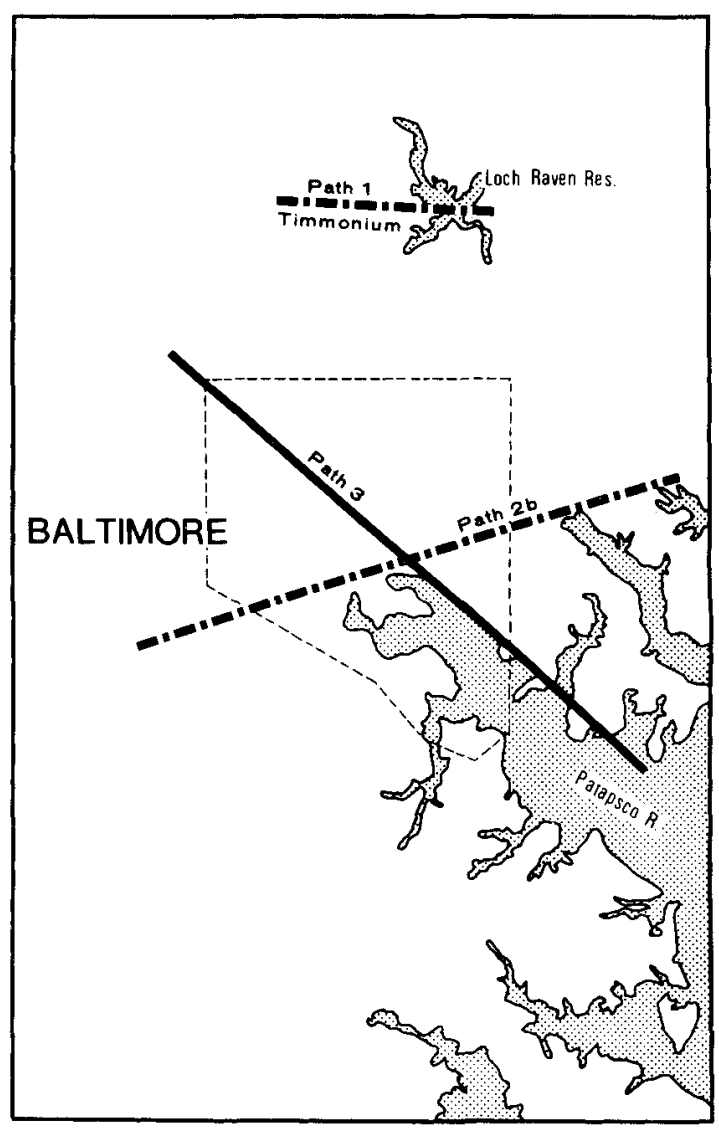

FIG. 1. Flightpaths over Baltimore for the imaging mission of May 11, 1972. Flightline 3 is discussed in detail.

the city using the water surface of Loch Raven Reservoir and the blacktop surface of a large parking lot as instrumented calibration targets. New but still unused concrete pavement of freeway structures facilitated later determination of surface albedos. Two flightlines crossed the central business district (CBD) northeast to southwest and northwest to southeast with the latter, Flightline 3, including inner residential areas, the CBD, industrial and commercial areas, an arm of the Patapsco River estuary, and Sparrows Point steel mill (Fig. 1).

Radiation data were collected in the following spectral bands: $0.58-0.64,0.62-0.70,1.0$ 1.4 , and 9.8-11.7 micrometers $(\mu \mathrm{m})$. Weather conditions during the day were dominated by a polar continental air mass with low vapor pressures, low turbidity, and absence of cloud cover which permitted substantial solar input for this time of year. 


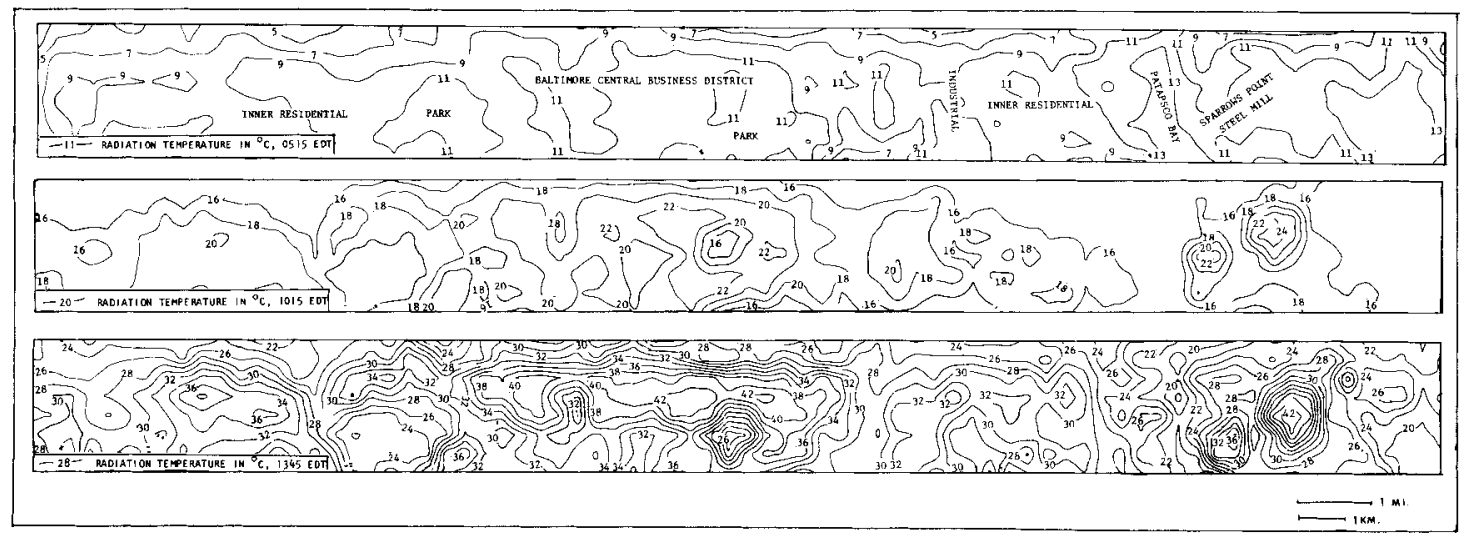

FIG. 2. Diurnal development of the Baltimore heat island. Isarithmic displays show radiation temperatures in degrees Celsius for sunrise, mid-morning, and the warmest period of the day for Flightline 3 (image of flight path on Fig. 3 ).

To calibrate the scanner to the surface in subsequent data processing, radiances of ground targets were measured as radiation temperatures at times of overflight as were the spectral reflectivities of the surfaces, the intensity and spectral distribution of the downwelling sunlight, and the intensity of global atmospheric longwave downradiation. Meteorological conditions of the lower atmosphere were also checked to permit compensation for the graywindow modification of surface-emitted signals by the air column intervening between the surface and sensor. ${ }^{1}$ Low water vapor content and turbidity, however, made this modification minimal.

Upwelling energy in the spectral bands listed was recorded by the scanner onto magnetic tape pixel by pixel, each about 9.5 meters square; that is, an average value was recorded for areas of this size.

\section{Maps of Energy-Exchange Phenomena}

In subsequent data processing, maps showing various surface energy-exchange phenomena were made both directly from magnetic tape, solely by use of computers, and from transparencies derived from tape data using initial optical techniques. Isarithmic displays were made from the photo-transparency images

1 R. W. Pease, S. R. Pease, and R. H. Alexander, Mapping Terrestrial Radiation Emission with the $R S$ 14 Scanner, Technical Report 4, U. S. G. S. Contract No. 14-08-0001-11914, University of California, Riverside $(1970), 27$ pp.
(Figs. 2 and 3). Line-printed graymaps were made directly from a digitized version of the original analog scanner recording tape (Fig. 5). ${ }^{2}$

An initial step in making the maps was the generalization or smoothing of data to achieve spatial averages. The method used was according to type of input of data to the automated cartographic system. For the optical read-in from transparencies, block filtering to a 0.40 kilometer ground resolution was provided by a 6.4 square millimeter aperture of a custom fabricated densitometer attached to the cursor of an $\mathrm{x}-\mathrm{y}$ digitizer. Where the input was directly from magnetic tapes, smoothing of digitized pixel data involved the use of block and sliding filters at the computer level. First, four pixels on each of four lines ( 16 pixels) were block filtered. Now reduced in number by a factor of sixteen, data points were further smoothed by the recursive use four times of a three-by-three Hanning sliding filter which reduced spatial variability but not the amount of significant information. The computer smoothing techniques allowed surface elements on a graymap to retain their basic relative size and shape while spatially high frequency noise was removed, resulting in a statistical surface that is essentially dasymetric. Urban heat islands, for example, appear less monolithic than on the

2 Isarithmic maps were produced by the University of California, Riverside, and line-pinted graymaps were produced by the Environmental Research Institute of Michigan. 

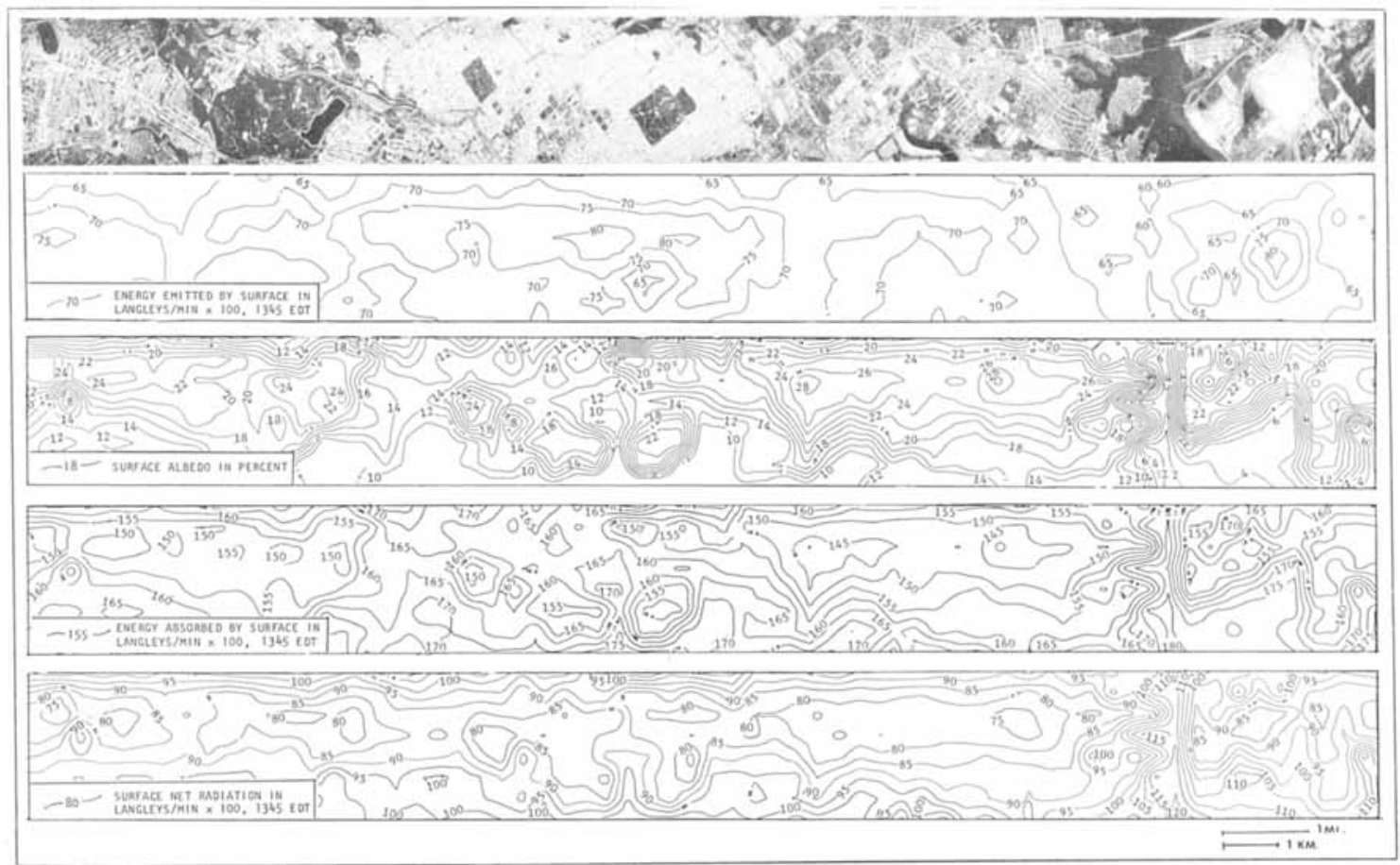

FIG. 3. Synoptic distributions of energy-exchange phenomena for Flightline 3 in the early afternoon (1345 EDT). The image is that of the thermal infrared band, 9.8 to 11.7 micrometers. The heat island of the Baltimore CBD (light tone) appears in the center with Patterson Park (dark tone) a prominent cool spot in the business district. Sparrows Point steel mill appears as a minor heat island on the right while the large cool area on the left is Druid Hill Park.

isarithmic displays which assume continuous gradients.

Maps showing thermal radiation (radiation temperature and radiant emission) are simplest to make since they are derived from a single band of scanner data. As an example, the buildup of a heat island over Baltimore is made from only the 9.8-11.7 $\mu \mathrm{m}$ band data for each flight time (Fig. 2). Construction is more complex for the series of maps which culminates in the distribution of net radiation (Fig. 3). By combining information from several of the scanner multispectral channels, assessment of surface albedos can be made. A sampling technique using two bands was employed, one for shorter wavelengths and the other for wavelengths longer than the rise of chlorophyll reflectance that centers at $0.725 \mu \mathrm{m}$. To match the partitioning of the solar spectrum at this wavelength, reflectivities derived from the $0.62-$ $0.70 \mu \mathrm{m}$ band were weighted sixty percent while those from the 1.0-1.4 $\mu \mathrm{m}$ or near infrared band were weighted forty percent to ob- tain overall surface albedos. ${ }^{3}$ Energy absorbed by the surface is the downwelling solar radiation, as modified by the unity-complement of the albedo, plus atmospheric downradiation, for convenience reduced by an average 0.95 surface emissivity. Surface radiant emission, a function of surface radiation temperature, is balanced against absorption to obtain net radiation.

Details of the construction of energy-related maps are described elsewhere. ${ }^{4}$ For the

3 S. R. Pease and R. W. Pease, Photographic Films as Remote Sensors for Measuring Albedos of Terrestrial Surfaces, Technical Report 5, U. S. G. S. Contract No. 14-08-0001-11914, University of California, Riverside (1972), p. 13.

4 R. W. Pease and D. H. Nichols, "Net Radiation and other Energy-Related Maps from Remotely Sensed Imagery," Proceedings of the American Society of Photogrammetry, 41st Annual Meeting (1975), pp. $322-37$, describes the making of the isarithmic maps. F. J. Thomson and R. J. Dillman, Baltimore, Maryland, Radiation Balance Mapping (Nov. 1973), unnumbered technical report, Environmental Research Institute of Michigan, describes making the lineprinted graymaps. 
Table 1.-Necessary Simulation Data

Meteorological variables $(M)$
Station pressure
Incoming solar radiation
Incoming thermal radiation
Mean air temperature
Mean relative humidity
Mean wind velocity
Geographical terrain parameters $(C)$
Substrate thermal diffusivity
Substrate thermal conductivity
Surface albedo (effective)
Surface aerodynamic roughness
Surface wetness

Sources: Outcalt, op. cit., footnote 7, and Myrup, op. cit., footnote 7 .

isarithmic displays, values of calibration targets were relied upon to compensate automatically for the modification of surface emission by air in the optical path of the scanner. ERIM, in producing the graymaps, used the internal or self-calibration capability of the M-7 scanner and of necessity compensated for the air effect.5

The maps made by these techniques are essentially synoptic since all data used in making them were collected during a few minutes of time. This is in contrast to maps made by traditional ground observations which are often derived from averages of data collected over an extended time period. The synoptic maps enable the analysis of the dynamics of urban thermal response.

\section{MODELING IN URBAN CLIMATOLOGY}

A central question in urban climatology pertains to the ways land use interacts with weather to modify urban climates. ${ }^{\circ}$ The mean surface temperature in any area of urban terrain, for example, is a unique response to local weather and the physical properties of the earth's surface and substrate. Present technology permits the numerical simulation of surface thermal and energy balance regimes as a function of local

5 A method for making this correlation is described in R. W. Pease, "Mapping Terrestrial Radiation Emission with a Scanning Radiometer," Proceedings of the Seventh International Symposium of Remote Sensing of the Environment (1971), pp. 501-10.

$6 \mathrm{~S}$. Outcalt, "A Reconnaissance Experiment in Mapping and Modeling the Effect of Land Use on Urban Thermal Regimes," Journal of Applied Meteorology, Vol. 11 (1972), pp. 1369-73. meteorological observations and of the radiative, aerodynamic, and thermal properties of the near surface environment (Table 1 ).

The straightforward modeling approach used by Myrup was adapted to this experiment because it includes all essential energy-related phenomena. It also breaks down into numerical algorithms that conserve computer time when many grid-point calculations must be made to create a spatial distribution. ${ }^{7}$ Although the Myrup model provided the original approach for our simulation, it was modified to suit the needs of this study.

The method hinges on the specification of all the variables needed to calculate the components of surface energy transfer based on the meteorological (M) and geographical $(\mathrm{G})$ data (Table 1). The four components of surface energy transfer are net radiation ( $R$ ), and the soil $(\mathrm{S})$, sensible $(\mathrm{H})$, and latent $(\mathrm{L})$ heat fluxes. These can be specified as transcendental

${ }^{7}$ The pioneering use of computers was by $\mathbf{M}$. $\mathbf{H}$. Halstead in "A Preliminary Report on the Design of a Computer for Micrometeorology" (with R. Richman, W. Covey, and J. Merryman), Journal of Meteorology, Vol. 14 (1957), pp. 308-25 and M. A. Estoque, "A Numerical Model of the Atmospheric Boundary Layer," Journal of Geophysical Research, Vol. 68 (1963), pp. 1103-13. The numerical simulation of surface energy budgets has progressed due to the efforts of several workers. More recent developments include L. Myrup, "A Numerical Model of the Urban Heat Island," Journal of Applied Meteorology, Vol. 8 (1969), pp. 908-18; T. M. Tag, "Surface Temperatures in an Urban Environment," Atmospheric Modification by Surface Influences, Part I, Department of Meteorology, Pennsylvania State University (1969), 72 pp.; W. G. Zdunkowski and D. C. Trask, "Applications of a Radiative-Conductive Model to the Simulation of Nocturnal Temperature Changes over Different Soil Types," Journal of Applied Meteorology, Vol. 10 (Oct. 1971), pp. 937-48; J. L. McElroy, "A Numerical Study of the Nocturnal Heat Island over a Medium-Sized Mid-latitude City (Columbus, Ohio)," Boundary Layer Meteorology, Vol. 3 (1973), pp. 442-53; M. A. Atwater, "Thermal Changes Induced by Urbanization and Pollutants," Journal of Applied Meteorology, Vol. 14 (1975), pp. 1061-71; and R. D. Bornstein, "The Two-Dimensional URBNET Urban Boundary Layer Model," Journal of Applied Meteorology, Vol. 14 (1975), pp. 1459-77. The Bornstein work also attempts a spatial expansion. Most models utilize close to the same inputs but handle the parameters in a slightly different manner. For details of the modification of the Myrup model consult S. Outcalt, "A Numerical Climate Simulator," Geographical Analysis, Vol. 13 (1971), pp. 629-36 and S. Outcalt, "The Development and Application of a Simple Digital Surface Climate Simulation," Journal of Applied Meteorology, Vol. 11 (1972), pp. 629-36. 
Table 2.-Computation of Geographical ParamETERS

\begin{tabular}{lll}
\hline \multicolumn{1}{c}{ Parameter } & \multicolumn{1}{c}{ Definition } & A Function of ... \\
\hline $\begin{array}{l}\text { Substrate } \\
\text { diffusivity and } \\
\text { conductivity }\end{array}$ & $\begin{array}{l}\text { Traditional } \\
\text { definition }\end{array}$ & Wetness fraction \\
$\begin{array}{l}\text { Surface albedo } \\
\text { (effective) }\end{array}$ & $\begin{array}{l}\text { Includes absorp- } \\
\text { tion of radiation } \\
\text { from vertical } \\
\text { surfaces }\end{array}$ & $\begin{array}{l}\text { Silhouette ratio } \\
\text { and obstruction } \\
\text { height }\end{array}$ \\
$\begin{array}{l}\text { Surface } \\
\text { aerodynamic } \\
\text { roughness }\end{array}$ & $\begin{array}{l}\text { computation of } \\
\text { turbulent fluxes }\end{array}$ & $\begin{array}{l}\text { Silhouette ratio } \\
\text { and obstruction } \\
\text { height }\end{array}$ \\
\hline
\end{tabular}

Sources: Lettan and Myrup, op. cit., footnote 9.

in surface temperature $(\mathrm{T})$ in the familiar energy conservation equation,

$$
\begin{aligned}
\mathrm{R}(\mathrm{G}, \mathrm{M}, \mathrm{T})+ & \mathrm{S}(\mathrm{G}, \mathrm{T})+\mathrm{H}(\mathrm{G}, \mathrm{M}, \mathrm{T}) \\
& +\mathrm{L}(\mathrm{G}, \mathrm{M}, \mathrm{T})=0 .
\end{aligned}
$$

A suitable numerical algorithm (intervalhalving or secant) is selected to carry out a search for that surface temperature which will drive the equation to a zero sum condition. Then, an explicit or implicit finite difference algorithm is employed to generate an update soil temperature/depth profile. Thus, at each iteration, the surface temperature and all of the components of surface energy transfer are outputs in addition to the substrate (soil) thermal profile.

An elaboration of the model requires the estimation of the geographical terrain parameters, easily accomplished by using sample urban tracts several blocks in area. These parameters are related to features of urban terrain which can be abstracted from stereo aerial photography, multispectral imagery and insurance maps by methods described in the literature. ${ }^{8}$ The relationships were derived from considerations based upon the earlier work of Lettau and Myrup. ${ }^{9}$ In brief, geographical parameters needed in the simulation are the products of three urban terrain factors: wet fraction, silhouette ratio, and obstruction height (Tables 2 and 3 ).

8 Outcalt, op. cit., footnote 7.

9 H. Lettau, "Note on Aerodynamic Roughness Parameter Estimation on the Basis of Roughness Element Description," Journal of Applied Meteorol$o g y$, Vol. 8 (1969), pp. 828-32; and Myrup, op. cit., footnote 7 .
Table 3.-Urban Terrain Factors

\begin{tabular}{ll}
\hline Factor & \multicolumn{1}{c}{ Description } \\
\hline Wet fraction & $\begin{array}{l}\text { That fraction of the terrain tract } \\
\text { in irrigated lawn and tree cover. }\end{array}$ \\
Silhouette ratio & $\begin{array}{l}\text { The ratio of the vertical silhouette } \\
\text { area in a tract to the horizontal } \\
\text { area of that tract. }\end{array}$ \\
Obstruction height & $\begin{array}{l}\text { The mean height of buildings and } \\
\text { vegetation which forms an ob- } \\
\text { struction to air flow and creates a } \\
\text { vertical silhouette which collects } \\
\text { radiation in addition to that ab- } \\
\text { sorbed on horizontal surfaces. }\end{array}$ \\
\hline Source: Outcalt, op. cit., footnote 8.
\end{tabular}

This method for estimating simulation inputs which utilizes appropriate meteorological data was first applied to farmlands, city center, new tract-home subdivisions, and old residential terrain blocks in Ann Arbor, Michigan, and its environs in a simulation of thermal response for two times on August 6, 1970 (2:52 a.m. and 11:44 a.m. EST). ${ }^{10}$ Inputs were based upon area-integrated thermal response means derived from thermal imagery collected by the Willow Run Laboratories (now ERIM). Differences between observed (scanner) and simulated temperature values ranged from $+0.5^{\circ} \mathrm{C}$ for farmland to $-1.5^{\circ} \mathrm{C}$ for the city center. In all cases the thermal rank was correct in the simulation and maximum differences were in the realm of fifteen percent of the total thermal range. This result was extremely encouraging and led to the application of the modeling technique to the Baltimore experiment, the results of which are summarized in a following section.

The model was later tested to see if the heat island effect at the city center could be generated in winter and if the physical basis for the clear weather thermal contrast was seasonally variable. ${ }^{11}$ This analysis indicated that surface wetness variations were largely responsible for the temperature contrast in summer, whereas the absorption of beam radiation by vertical walls was the most potent environmental factor in winter.

10 Outcalt, op. cit., footnote 6 .

11 S. Outcalt, "A Synthetic Analysis of Seasonal Influence in the Effects of Land Use on the Urban Thermal Regimes," Archiv fuer Meteorologie Geophysik und Bioklimatologie, Vol. 20 B (1972), pp. 25360. 
Table 4.-Application of Simulation Parameters

\begin{tabular}{|c|c|c|c|c|c|}
\hline Land Use & $\begin{array}{c}\text { Albedo } \\
\text { (percentage) }\end{array}$ & $\begin{array}{c}\text { Substrate } \\
\text { Diffusivity } \\
\left.\text { (in } \mathrm{cm}^{2} / \mathrm{sec}\right)\end{array}$ & $\begin{array}{c}\text { Wet } \\
\text { Fraction } \\
\text { (percentage) }\end{array}$ & $\begin{array}{c}\text { Surface } \\
\text { Roughness } \\
\text { (in cm) }\end{array}$ & $\begin{array}{c}\text { Silhouette } \\
\text { Ratio }\end{array}$ \\
\hline \multicolumn{6}{|l|}{ Low density } \\
\hline residential & 18 & .011 & 60 & 73 & .13 \\
\hline \multicolumn{6}{|l|}{ Medium density } \\
\hline residential & 18 & .0155 & 30 & 86 & .19 \\
\hline \multicolumn{6}{|l|}{ High density } \\
\hline residential & 14 & .0192 & 1 & 110 & .19 \\
\hline CBD & 15 & .0192 & 5 & 400 & .22 \\
\hline Commercial & 15 & .0192 & 5 & 78 & .02 \\
\hline Transportation & 15 & .0177 & 15 & 6 & .02 \\
\hline Urban parks & 23 & .0065 & 90 & 80 & .17 \\
\hline
\end{tabular}

Sources: Field observation by authors; Jenner, op. cit., footnote 13; Myrup, op. cit., footnote 14; and Nicholas, op. cit, footnote 12 .

Possible refinements of the model include the detailed analysis of the geometry of urban terrain and geographical parameterization. An example is a recently completed doctoral dissertation at the University of Maryland which demonstrates that aerodynamic roughness can be effectively estimated from urban land use characteristics. ${ }^{12}$ The internal structure of the computer simulators is being modified to produce increased computational efficiency and to provide more realistic sub-models of energy transfer processes. Work to date indicates that our general model is well constructed. It provides a valuable method for abstracting large amounts of field data and for evaluating the physical basis of urban thermal contrasts.

\section{THE COUPLED EXPERIMENT}

A portion of Flightline 3 was selected to show the methodology of the coupled experiment in which a simulated surface temperature map, produced from surface characteristics inferred by land use, is compared with an observed temperature map derived from remotelysensed data. The general approach in modeling urban temperature fields is based on the simulation of a set of temperatures associated with surface characteristics representative of a particular land use. The rationale for this method is that each land use type, with its individual mix of surface properties, generates an energy regime unique to that type.

12 F. W. Nicholas, Parameterization of the Urban Fabric: A Study of Surface Roughness with Application to Baltimore, Maryland, unpublished doctoral dissertation, University of Maryland, College Park, 1974.
The modeled temperature field was constructed in the following manner. A specific set of urban geographical terrain factors (surface roughness, substrate diffusivity, surface albedo, percentage of transpiring surface or wet fraction, and silhouette ratio) was estimated for each type of land use. Once temperatures for respective land uses were simulated, a forty to fifteen cell grid (each cell is $0.90 \mathrm{~km}^{2}$ ) was placed over the land use map of the study area and temperature values were plotted to match each use type occurring at grid intersections.

Values for the geographical terrain parameters were obtained for this study according to techniques outlined by Jenner except for surface albedo and substrate diffusivity (Table 4).$^{13}$ Albedo values for each land use type were ascertained from the observed or remotelysensed data displayed on Figure 3. Diffusivity values were obtained from Myrup and Morgan. ${ }^{14}$ In the surface budget simulation, an observed mean sky radiant temperature of $-5^{\circ} \mathrm{C}$ was used rather than a value $22^{\circ} \mathrm{C}$ under the mean air temperature as was the case in earlier versions of the model.

The land use classification employed was slightly modified from that of the U. S. Geological Survey. The residential classification was subdivided into low, medium, and high density categories and the CBD of downtown Balti-

${ }^{13} \mathrm{C}$. Jenner, Modeling the Effect of Land Use on the Urban Temperature Field, unpublished doctoral dissertation, University of Maryland, College Park, 1975.

14 L. Myrup and D. Morgan, Numerical Model of the Urban Atmosphere, Vol. 1, Contributions in Atmospheric Science, 4 (University of California, Davis, 1972), 237 pp. 

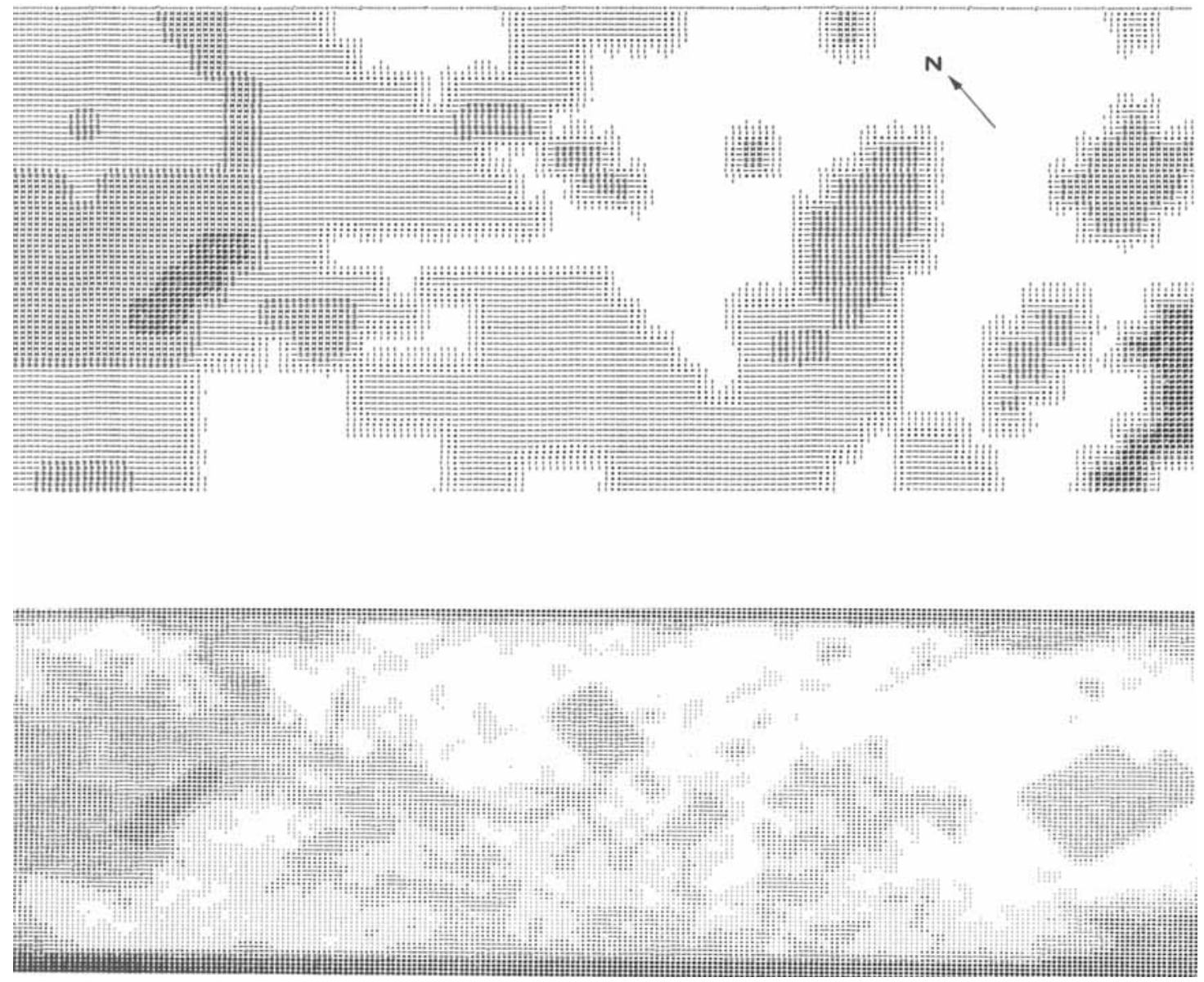

FIG. 4. A simulated distribution of radiation temperatures (top) compared with an "observed" or scanner-derived map (bottom). Both maps have the same scale along the flightline but only the simulated map is planimatric. The observed map is compressed transverse to the flightline because of the rolloff of straight scanline imagery due to the nonlinearities of the tangent function and the distortion of the line printer.

more was considered commercial land use. Open land was classed with parks, and temperatures for institutional use were calculated with a weighting of one-third commercial and twothirds park.

Simulated temperatures for the respective land uses for 1400 EDT of the flight date are mapped according to the grid method previously discussed (Fig. 4, Table 5). Temperatures for 600 intersections of the grid system were needed to make the map. The simulation is for only that portion of the flightpath displayed on Figure 3 which begins at the northern end of Druid Hill Park and extends southeasterly across a high density residential area on Baltimore's west side to the city CBD and Patter-
Table 5.- Simulated Surface Radiant Temperatures as Functions of Land Use for a Portion of FLIGHTLINe 3

1400 EDT, MAY 11, 1972

\begin{tabular}{lc}
\hline \multicolumn{1}{c}{ Land Use } & Temperature $\left({ }^{\circ} \mathrm{C}\right)$ \\
\hline Residential & \\
Low density & 24.3 \\
Medium density & 28.3 \\
High density & 37.2 \\
CBD & 25.6 \\
Commercial & 33.4 \\
Transportation & 40.3 \\
Urban parks & 20.4 \\
Institutional (schools, etc.) & 22.6 \\
Water surface & 15.0 \\
\hline
\end{tabular}



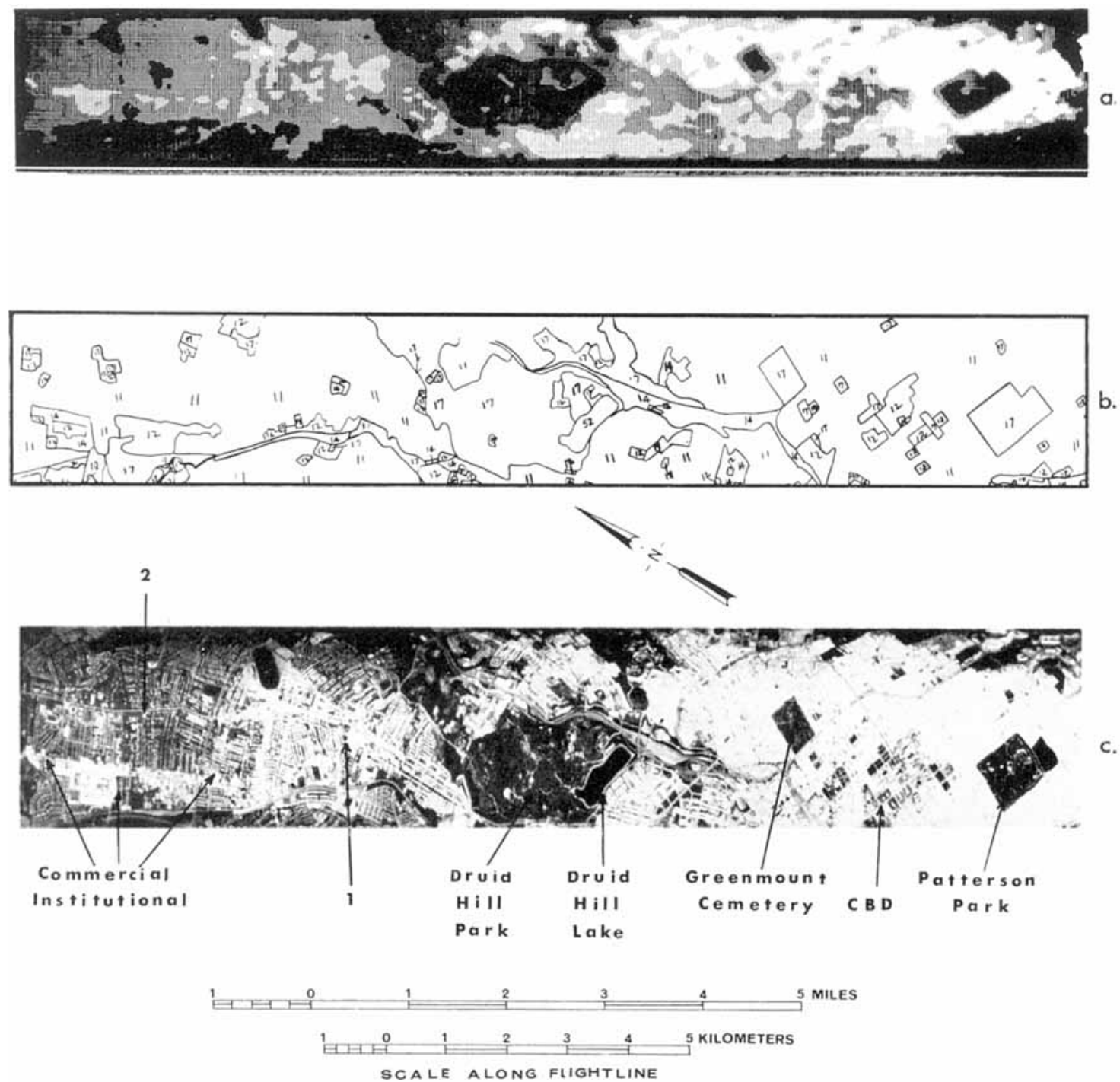

FIG. 5. Effects of the urban land use mosaic: $a$. scan image of the 9.8 to $11.7 \mu \mathrm{m}$ band (1345 EDT) showing surface radiant temperatures in tones of gray with darkest tones the lowest temperatures; $b$. a land use map of the imaged area; $c$. digitized map of surface radiant temperatures. The land use designations are adapted from J. R. Anderson, E. Hardy, and J. Roach, A Land Use Classification System of Use with Remote Sensor Data, U. S. G. S. Circular 671 (1972) and are coded as follows: 11, residential; 12, commercial and services; 14, transportation, communications, and utilities; 17, urban green areas (parks, cemeteries, etc.); 31 , deciduous forest; and 52, lakes.

son Park (Fig. 5). The map has seven class intervals in which the simulated temperature range is from $15^{\circ}$ to $40.3^{\circ} \mathrm{C}$. The gray shading follows the same tonal progression as on the observed thermal graymap, with the darkest tones indicating the coolest temperatures.

The relative spatial association of simulated versus observed thermal patterns is good even though no attempt has been made to correct for scanner distortions in the maps from remotely-sensed data. Druid Hill Park and Lake are cool and temperatures warm to the southeast where high density residential use occurs. Cool islands of vegetation, such as Greenmount Cemetery and Patterson Park, break the predominant high temperatures of the CBD. Ches- 


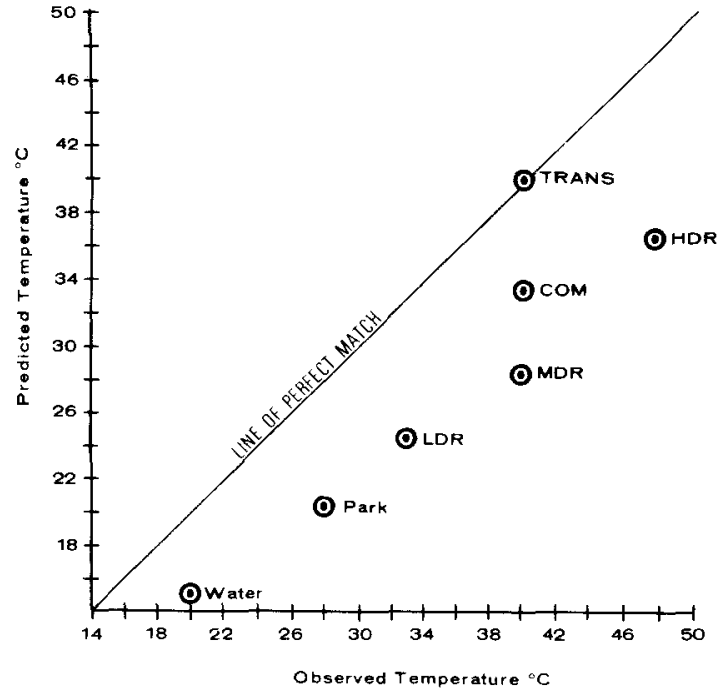

Fig. 6. Correlation between simulated and observed temperatures for various land uses. Coding of points is: TRANS, transportation; COM, commercial; HDR, MDR, and LDR are high, medium, and low density residential land uses, respectively.

apeake Bay provides the coolest temperatures simulated.

Of the maps shown in this study, only the simulated map is truly planimetric. If all are considered to have the same scale along the flightpath, the transverse scale for the scannerproduced maps is compressed. This results from straight scanline geometry which incorporates the non-linearities of the tangent function in an inverse manner. If the flightpath scale is considered as unity, the transverse scale factor will be a non-linear 0.77 .

We feel that the simulation model performs an intriguing job of replicating the temperature field observed at flight time. The distribution of surface temperature patterns is approximately the same as on the scanner-derived maps although the coarseness of the grid-point spatial expansion precludes accurate correlation of shapes. Temperature gradients are approximately the same for both mapping approaches although absolute values of high and low temperature centers differ. In other words, hierarchical orders of temperature range match, but with somewhat different values.

With respect to absolute values, the simulation model consistently underpredicted the observed temperatures for all land use types considered (Fig. 6). The underprediction, however, may well result from the conservative na- ture of the model which, like the Myrup original, assumes that the atmospheric damping depth for temperature remains constant for the twenty-four hour period of simulation. A constant damping depth produces a steeper than rational lapse rate during the afternoon hours which simulates greater amounts of energy removal from the surface than would normally occur in nature. From this it follows that modeled surface temperatures would be underpredicted. The similarities of the predicted range of approximately $25^{\circ} \mathrm{C}\left(15.0^{\circ}-40.3^{\circ} \mathrm{C}\right)$ with the $28^{\circ} \mathrm{C}$ observed range and the parallel nature of the hierarchic rankings are still considered good results for a model not yet in final form.

In evaluating the results, it must be kept in mind that the simulations were tied to the characteristics developed for specific land use types. Results thus test not only the validity of spatial expansion of energy budget simulation but the validity of relating surface energy-related phenomena to land use as well.

\section{URBAN LAND USE CLIMATOLOGY}

Both the numerical simulations and the mapping from remotely-sensed data indicate that the monolithic nature of heat islands, frequently reported in the literature, may be an artifact of ground-based measurement systems. In the case of thermal transects made in automobiles, the temperature near the surface is a product of the thermal radiation trap created by building height and predominant surfaces of asphalt and concrete. Measurements are taken in a thermal cavity that excludes the radically different thermal environment comprised of off-street building roofs and other objects. In contrast, the linescan image records energy states of active meteorological surfaces for business districts and other urban land uses. The combination of numerical modeling which can simulate varied urban surfaces with actual mapping of surface thermal states points the way toward the development of a new subdiscipline, "urban land use or terrain climatology," in which theoretical and observational techniques are combined to gain a sound understanding of the physical nature of surface thermal contrasts. The sensitivity of urban thermal systems to variation of physical parameters can be tested numerically and checked against observational reality.

In this light, it is appropriate to examine Figure 5 in more detail. The scan image depicts 
qualitatively and the map depicts quantitatively the urban surface "skin" temperatures. In both cases, dark tones are the coolest temperatures and as tones lighten the temperature increases. Digitized into temperature categories, the map offers a sampling grid net that is rarely obtained in urban climatic analysis with a grid density that minimizes interpolation errors. The nature of the surface appears to have a significant influence on the temperature response. A gradient of increasing temperatures is displayed from the northwest suburbs to the high density residential and central business district in the southeast. Rather than a monolithic thermal plateau, the urban surface is a patchwork of interlaced pockets of cooler and warmer temperatures which correlate markedly with land use types. Arrows on the figure point to examples of surface effects. The water surface of Druid Hill Lake, for example, highlights the coolest temperature $\left(20^{\circ} \mathrm{C}\right)$. Vegetated areas, such as Druid Hill Park, Greenmount Cemetery, and Patterson Park, stand out as areas noticeably cooler than the commercial and industrial land uses where radiation temperatures range from $45^{\circ}-55^{\circ} \mathrm{C}$. The effects of vegetation juxtaposed with residential structures, as occurs with innercity residential land use, can be seen at the northwest or left hand end of the image and maps. In area 2 , surface temperatures are lower by $10^{\circ}-15^{\circ} \mathrm{C}$ than in area 1 due to lower house densities and vegetated surfaces that are thus proportionately greater. The effects on temperature of arterial, commercial, and institutional buildup are particularly apparent.

With respect to mapped distributions of energy-exchange phenomena other than simple thermal radiation, Flightline 3 southeast across Baltimore includes a variety of useful surfaces: inner residential, $\mathrm{CBD}$, parks, the water surface of the arm of the Patapsco River estuary, and heavy industry in the form of Sparrows Point steel mill. For these, albedo differences are the most significant controls for patterns of absorbed energy and net radiation. When downwelling radiation from the sun and atmosphere is assumed to be evenly distributed, albedo diversity establishes the pattern of energy absorption. This is because the diversity range of energy emitted for the urban sample of Figure 3 is only 0.20 langleys/minute, less than half the 0.50 langleys/minute range of energy absorbed, and because absorption is primarily controlled by albedos. This discrepancy, due to nonradiant energy transfers away from the interface, represents net radiation.

A comparison of the various energy-exchange maps helps explain the diversity of temperatures associated with urban land use and gives considerable insight into the injection of natural energy into urban thermal systems. Vegetated surfaces, such as parks, appear as albedo "brightspots" in the Baltimore CBD. Since albedo is here considered as pertaining to the entire spectrum of daylight, the high reflectivity in the near infrared of chlorophyll-filled plant tissue (forty to fifty percent) gives parks albedo values of over twenty percent despite generally low visible reflectivities. Surrounding CBD surfaces are typically pavement, roofing materials, and blacktop parking lots which have generalized reflectivities that are low in both spectral sampling bands; albedos here average around twelve percent. Comparatively high albedos make downtown parks relatively poor absorbers, a fact of interest which gives another reason (other than the transfer of heat to latent energy) why parks are relatively cool spots in summer. Furthermore, because of the latent energy transfer, a park is generally considered to have a substantially higher net radiation balance than surrounding nonvegetated areas. This does not appear to be the case in the synoptic map analysis, perhaps because of the lowered absorption of solar energy.

Other high albedo urban terrains which are poor absorbers of solar radiation in the vegetated season are residential areas (especially those with light-colored roofs and grass-covered yards), certain industrial/commercial areas where large light-colored roofs reflect well across the solar spectrum, and a petroleum tank farm where white tanks are set in bare soil sumps.

With respect to the distribution of net radiation, good absorbers generally are warm by midafternoon and are good emitters. Under these conditions, the radiation balance can only be moderate such as in the CBD where hard surfaces and thermal cavities give positive values of only 0.70 to 0.80 langleys/minute. Highest values occur over the water surfaces of the bay estuary and reach 1.25 langleys/minute. Absorption of downwelling radiation is high but high thermal capacity and tidal exchange of water with nearby Chesapeake Bay cause the 
water to remain cool and it is a relatively poor emitter. Because of the thermal inertia and tidal exchange, this seemingly high rate of injection of energy into the urban thermal system has questionable local significance.

The land use surface provided by Sparrows Point steel mill has a net radiation balance substantially higher than other industrial-commercial areas $(1.05 \mathrm{ly} / \mathrm{min}$. $)$. This appears something of an anomaly because, although the albedo is particularly low, the nature of surfaces and the addition of man-made heat should yield high values of energy emission. The less generalized graymap demonstrates its utility here; it shows the mill itself to have a balance approximately like that of the CBD but the overall mill area value is raised by a large cooling pond on the premises.

This type of analysis of the energy-exchange phenomena associated with urban land use may have a positive impact on man's manipulation of the urban terrain. As an example, it indicates that modern tract-home subdivisions that lack tree plantings may have environmental thermal responses as regards human comfort nearly as poor as those of the inner city commercial and industrial terrains. This could be important for decisions relating to the creation of new housing tracts which destroy older residential areas that form a cold annulus about the city center.

The type of analysis described here may eventually explain the somewhat confused mass of empirical data regarding the seasonal and diurnal variations in the heat island effect. Further, the work strongly suggests that the physical basis of the heat island is both geographically and temporally variable and that an explanation suitable for London in winter may not be suitable for New Orleans, Tucson, or even London in summer. Thus, there is danger in subjecting urban heat island phenomena to explanations by universal hypotheses. In short, the system is nonlinear and its sensitivity to such factors as increased park area (wetness) is not temporally or spatially stationary but depends on the values that result from urban structures and local weather. All of the thermal contrasts discussed here have been produced without considering the effects of the injection of fossil fuel heat or the alteration of atmospheric radiative properties by pollution.

\section{THE FUTURE}

Various urban land uses are potent controls of the evolutionary structure of a two-dimensional surface thermal field under clear, calm weather. No attempt has been made as yet to model other synoptic conditions. Results of the simulation experiment indicate that under anticyclonic conditions in which the regional or synoptic scale wind velocity is reduced and the sky is cloudless, the local wind field develops from the spatial contrast in surface temperatures controlled largely by the land use mosaic. Pollutants are dispersed in accordance with the local wind field because they have been entrapped by thermal inversion in the lower layers of the atmosphere where local winds provide the air movement.

This argument suggests that a considerable effort should be launched to develop a coupled mesoscale atmospheric/surface modeling technology. Such a model eventually could incorporate a point source pollution diffusion model in which the three sections of the overall model structure (surface thermal, mesoscale atmospheric, and air pollution diffusion ) could interact or modulate each other at each iteration. Geographers should play an important role in the terrain parameterization portion of these critical model development experiments. The generalization level of spatial filtering of land use effects to which the wind field responds is a uniquely geographical problem. ${ }^{15}$

Synoptic maps of energy-exchange phenomena made from imagery obtained in airborne or satellite platforms are potentially useful inputs to test theoretical or computer-derived urban thermal models and to create observational model elements. Problems posed by the remotely-sensed maps and data can be tested by simulation. It is conceivable that observed data can be automatically integrated with simulated data to facilitate synoptic analysis of urban land use energy regimes. It should be noted that the maps displayed in this report represent only a single set of synoptic conditions. Other annual and diurnal times must be analyzed by observational and simulation techniques.

The climatic modification problem is one of

15 W. R. Tobler, "Geographical Filters and their Inverses," Geographical Analysis, Vol. 1 (1969), pp. 234-53. 
both atmospheric and surface effects. Surface ogy that can be utilized in the creation of land use effects are particularly significant be- planned urban terrain which should reduce cause they are subject to human manipulation. climatological hazards to human health and A new research environment has been estab- decrease the energy expended on heating and lished by current space and computer technol- cooling urban space. 